\title{
Nth Order Voltage Mode Active-C Filter Employing Current Controlled Current Conveyor
}

\author{
Ashish Ranjan, Sajal K. Paul \\ Department of Electronics Engineering, Indian School of Mines, Dhanbad, India \\ E-mail: \{ashish.ism, sajalkpaul\}@rediffmail.com \\ Received January 4, 2011; revised February 21, 2011; accepted March 7, 2011
}

\begin{abstract}
This paper proposes an nth order (where $n=2,3, \cdots, n$ ) voltage mode active-C filter using n number of current controlled current conveyors (CCCIIs) and n number of equal valued grounded capacitors. The proposed topology can implement both band pass and low pass responses without alteration of any components. The filters offer the following important features: use of minimum number of current controlled current conveyors (CCCIIs) and passive components, no matching constraint, use of all grounded capacitors and absence of external resistor suitable for integration, cut off frequency can easily be electronically adjusted using AMS $0.35 \mu \mathrm{m}$ CMOS technology. PSPICE simulation results of third order band pass and low pass responses are provided. The results are found to agree well with the theory.
\end{abstract}

Keywords: Analog Filters, Active-C Filter, Higher Order Voltage Mode Filter, CCCII

\section{Introduction}

Nowadays, current conveyors play an important role for the realization of various analog signal processing circuits and systems. They are accepted to have high performance properties such as wide signal bandwidth, high dynamic range, low power consumption and occupy less chip area [1,2]. The basic second generation current conveyor (CCII) does not have in built tuning property, whereas second generation current controlled current conveyor (CCCII) possesses this property because of the adjustability of intrinsic resistance at port X of CCCII by bias current [3-5]. Already a number of analog biquadratic filters have been reported in [6-9] and references cited there in. However, the nth order filter can be flexibly used to realize any higher order filter function and hence serves a wide range of applications. Higher order filters can be obtained by various methods such as cascading of lower order filters or state variable technique or signal flow graph. Already a number of current conveyor (CCII or CCCII) based higher order current mode [10-14] and voltage mode [15-18] filters have been reported. As this paper is concerning higher order voltage mode filters, hence only the study of the features of already reported higher order voltage mode filters [15-18] are made in Table 1.
In this work, an attempt is made to propose a new nth order (where, $n=2,3, \cdots, n$ ) voltage mode filter. Both low pass and band pass responses can be obtained from the same topology using n CCCIIs and grounded n capacitors. It does not require any resistor. The proposed topology is an active-C filter and hence ideal for IC implementation. The use of CCCIIs in the circuit provides electronic tunability [5] of the filter parameters.

\section{Circuit Description}

The circuit symbol of the DOCCCII is shown in Figure 1 The port relationship of a DOCCCII can be defined as

$$
I_{Y}=0, V_{X}=V_{Y}+I_{X}\left|R_{X}\right|, I_{Z \pm}= \pm I_{X}
$$

where, the positive and negative signs define a positive and a negative DOCCCII respectively. In this equation $R_{X}$, the intrinsic series input resistance of the conveyor at $X$ port is electronically tunable via $I_{0}$ of the CMOS based CCCII shown in Figure 2 and $R_{X}$ may be defined as [5]

$$
\begin{gathered}
R_{x}=\frac{1}{g_{m 2}+g_{m 4}} \\
g_{m i}=\sqrt{2 \beta_{i} I_{0}} \quad(i=2,4) \\
\beta_{i}=\frac{\varepsilon_{0} \varepsilon_{i n s} \mu_{i} W_{i}}{t_{o x} L_{i}}
\end{gathered}
$$


Table 1. Comparative study of the available nth order voltage mode filter.

\begin{tabular}{|c|c|c|c|c|c|c|c|}
\hline Ref. No. & $\begin{array}{c}\text { Active } \\
\text { element used } \\
\text { and number of } \\
\text { active } \\
\text { elements } \\
\text { required }\end{array}$ & $\begin{array}{l}\text { Number of } \\
\text { capacitors } \\
\text { required }\end{array}$ & $\begin{array}{l}\text { Number of } \\
\text { resistors } \\
\text { required }\end{array}$ & $\begin{array}{l}\text { All passive } \\
\text { elements are } \\
\text { grounded }\end{array}$ & $\begin{array}{l}\text { In built tunability } \\
\text { of filter } \\
\text { parameters }\end{array}$ & $\begin{array}{l}\text { Types of filter } \\
\text { implemented }\end{array}$ & $\begin{array}{l}\text { Require to } \\
\text { change the } \\
\text { hardware to } \\
\text { change filter } \\
\text { type }\end{array}$ \\
\hline 15 & CCII, $3 n-2$ & $n+1$ & $3 n-1$ & Yes & No & Universal filter & Yes \\
\hline 16 & CCII, $n+1$ & $n$ & $n+2$ & No & No & Low pass & $\begin{array}{c}\text { Not } \\
\text { Applicable }\end{array}$ \\
\hline 17 & CCII, $n+2$ & Minimum & $2 n+3$ & No & No & Universal filter & Yes \\
\hline 18 & CCCII, $n+1$ & $n$ & 1 & Yes & Yes & Low pass & $\begin{array}{c}\text { Not } \\
\text { Applicable }\end{array}$ \\
\hline Proposed & CCCII, $n$ & $n$ & Nil & Yes & Yes & $\begin{array}{c}\text { Low pass \& } \\
\text { Band pass }\end{array}$ & No \\
\hline
\end{tabular}

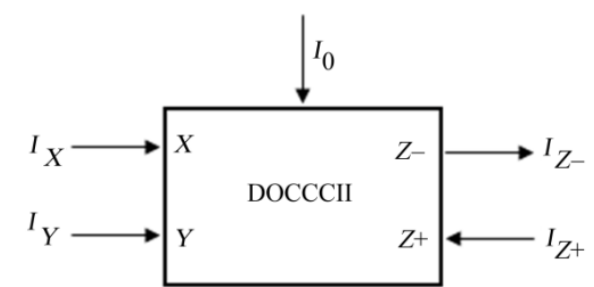

Figure 1. Block diagram of DOCCCII.

where, $g_{m 2}$ and $g_{m 4}$ are the transconductances of $\mathrm{M}_{2}$ and $\mathrm{M}_{4}$ respectively, $I_{0}$ is bias current of DOCCCII. The proposed voltage mode nth order filter circuit is shown in Figure 3.

The routine analysis of the circuit of Figure 3 gives the transfer function for an nth order filter as

$$
V_{\text {out }}=\frac{V_{\text {in1 } 1}-s V_{\text {in } 2} R_{x} C}{D(S)}
$$

where

$$
\begin{aligned}
& D(S)= \\
& a_{n n}\left(R_{x}^{n} C^{n}\right) s^{n}+\left[\sum_{j=1}^{n-2} \mathrm{a}_{n(n-j)}\left(R_{x} C\right)^{n-j} s^{n-j}\right]+a_{n 1} R_{x} C s+a_{n 0} \\
& n=2,3, \cdots, n \\
& a_{n n}=1 \\
& a_{n(n-j)}=a_{(n-j)(n-j)}+a_{(n-j)(n-j-1)} \quad(j=1,2, \cdots, n-2) \\
& a_{n 1}=2 \\
& a_{n 0}=1
\end{aligned}
$$

From above equations we can see that specialization in the numerator of (5) results in the following filter responses:

\section{1) Low pass Response}

- At $V_{\text {out }}$ with $V_{i n 1}=V_{\text {in }}$ and $V_{\text {in } 2}=0$

2) Band pass Response

- At $V_{\text {out }}$ with $V_{\text {in } 1}=0$ and $V_{\text {in } 2}=V_{\text {in }}$

Hence, the proposed circuit gives an inverted nth order band pass filter and nth order low pass filter from the same topology.

As an example, a third order transfer function

$$
V_{\text {out }}=\frac{V_{\text {in1 } 1}-s V_{\text {in } 2} R_{x} C}{s^{3} R_{x}^{3} C^{3}+3 s^{2} R_{x}^{2} C^{2}+2 s R_{x} C+1}
$$

is realized using (5)-(11) and the corresponding third order circuit obtained from the nth order circuit of Figure 3 is given in Figure 4.

With $V_{i n 1}=V_{i n}$ and, Equation (12) simplifies to

$$
V_{\text {out }}=\frac{V_{\text {in }}}{s^{3} R_{\mathrm{x}}^{3} C^{3}+3 s^{2} R_{x}^{2} C^{2}+2 s R_{x} C+1}
$$

which is a low pass response.

Similarly, with $\mathrm{V}_{\mathrm{in} 1}=0$ and, Equation (12) simplifies to

$$
V_{\text {out }}=\frac{-s V_{\text {in }} R_{x} C}{s^{3} R_{x}^{3} C^{3}+3 s^{2} R_{x}^{2} C^{2}+2 s R_{x} C+1}
$$

which is a band pass response.

The forth order filters is obtained by adding section shown in Figure 5 between $2^{\text {nd }}$ and $3^{\text {rd }}$ CCCII- of Figure 4. Similarly, fifth and higher order filters are obtained by adding one section shown in Figure 5 for each higher order.

Comparision of the available nth order filters [15-18] and the proposed one is given in Table 1. It reveals that the proposed circuit uses minimum number of current conveyors and passive components and no resistor. It can realize both band pass and low pass responses in contrast to only low pass response in $[16,18]$ and does not require to change any hardware to change filter type. The uni- 


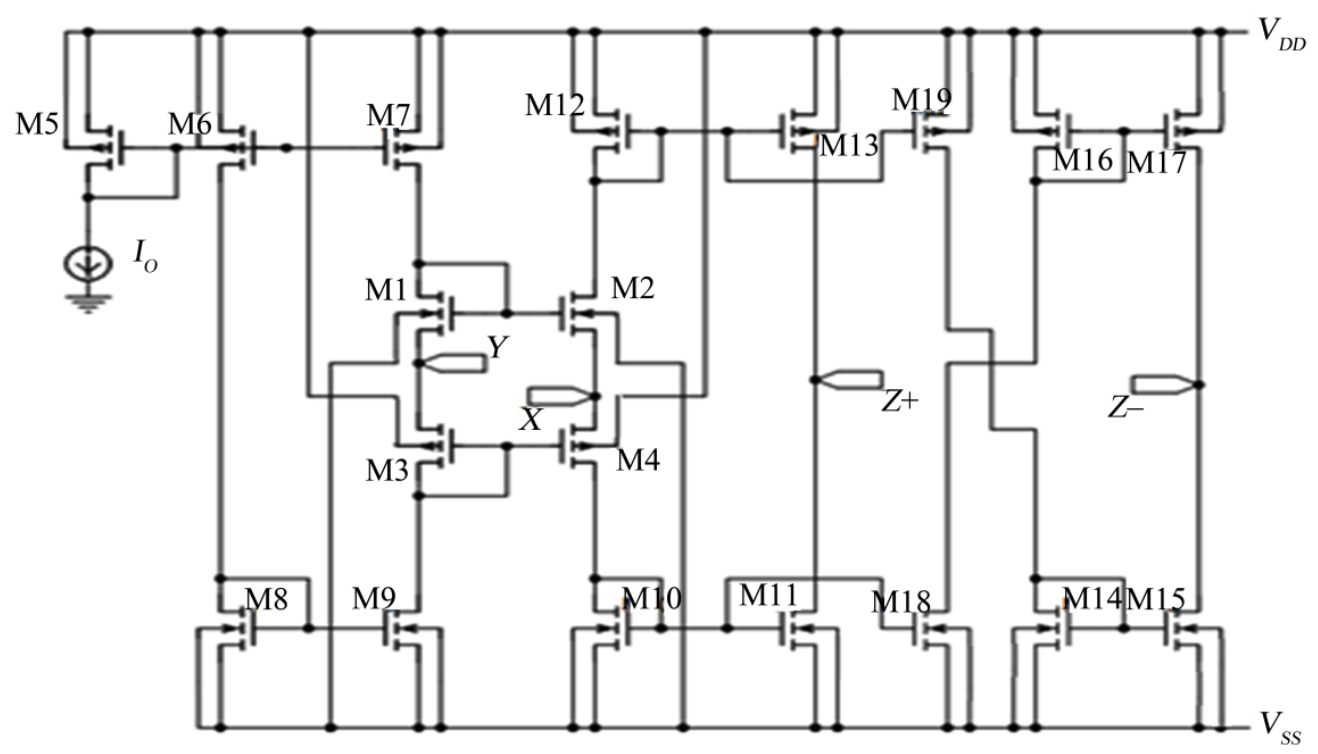

Figure 2. Internal structure of DOCCCII.

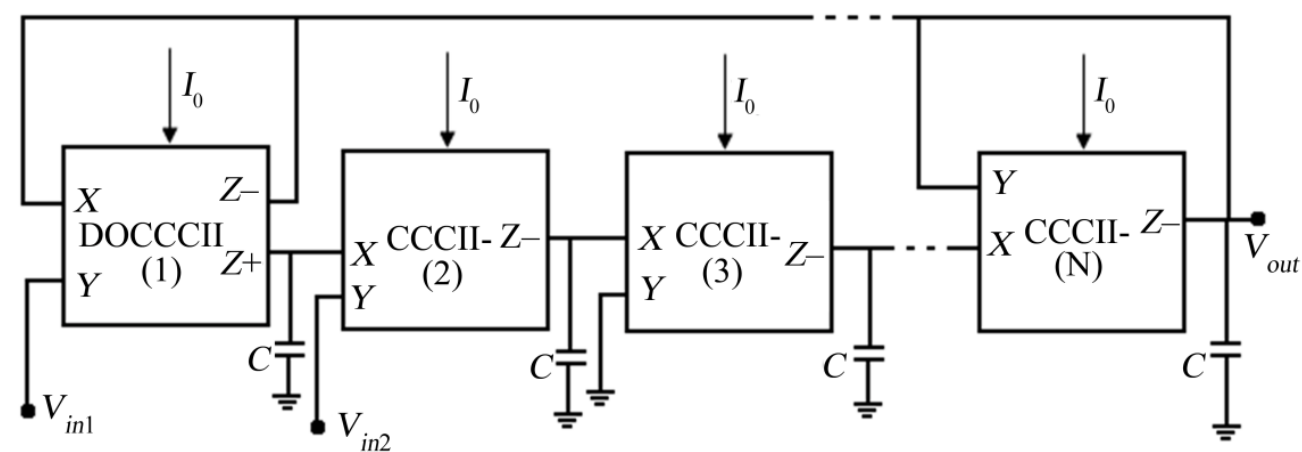

Figure 3. Proposed voltage mode nth order low pass and band pass filters.

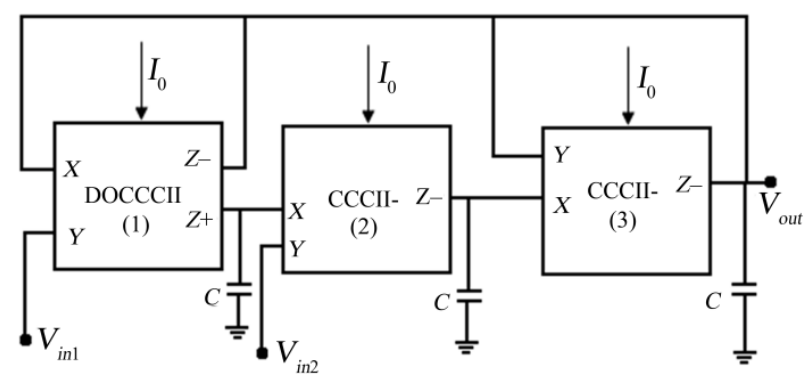

Figure 4. Proposed voltage mode third order low pass and band pass filters.

versal filters realized by structures in [15,17] are attractive, but the changing of the filter type would required the change of hardware of the filter circuits. Hence they are not suitable for monolithic IC implementation.

\section{Simulation and Results}

To verify the theory, the proposed voltage mode nth or-

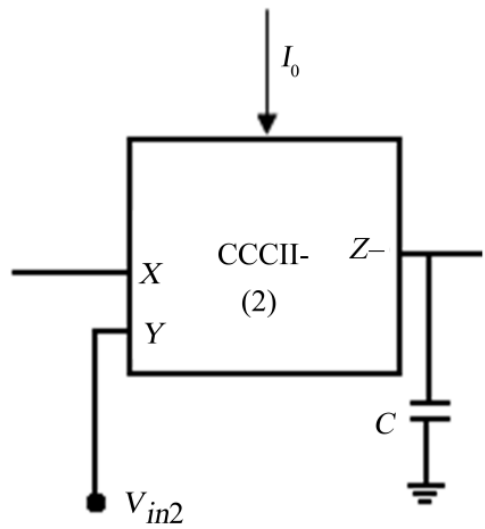

Figure 5. Section to be added for higher order filter.

der filter circuit is simulated with PSPICE using $0.35 \mu \mathrm{m}$ AMS CMOS based CCCII circuit given in Figure 2 [5] with supply voltage of \pm 2.5 volts and aspect ratio of transistors as given in Table 2.

As an example, a third order low pass filter and a band 
Table 2. MOS dimensions used in the circuit.

\begin{tabular}{ccc}
\hline Transistors & $W(\mu \mathrm{m})$ & $L(\mu \mathrm{m})$ \\
\hline $\mathrm{M}_{1}, \mathrm{M}_{2}$ & 20 & 0.35 \\
$\mathrm{M}_{3}, \mathrm{M}_{4}$ & 60 & 0.35 \\
$\mathrm{M}_{5}, \mathrm{M}_{6}, \mathrm{M}_{7}$ & 30 & 2 \\
$\mathrm{M}_{8}, \mathrm{M}_{9}$ & 10 & 2 \\
$\mathrm{M}_{10}, \mathrm{M}_{11}, \mathrm{M}_{14}, \mathrm{M}_{15}$ & 10 & 1 \\
$\mathrm{M}_{12}, \mathrm{M}_{13}, \mathrm{M}_{16}, \mathrm{M}_{17}$ & 30 & 1 \\
\hline
\end{tabular}

pass filter are obtained with $C=50 \mathrm{pF}$ and $I_{0}=200 \mu \mathrm{A}$. Frequency responses of the proposed low pass and band pass filters are shown in Figure 6 and Figure 7 respectively. The response for the low pass filter exhibits a $-60 \mathrm{~dB} / \mathrm{dec}$ slope for frequencies higher than $\mathrm{f}_{0}$. The response for the band pass filter, as shown in Figure 7, exhibits an asymmetrical third order nature with a slope of $20 \mathrm{~dB} / \mathrm{dec}$ for frequencies lower than $\mathrm{f}_{0}$ and $-40 \mathrm{~dB} / \mathrm{dec}$ for frequencies higher than $\mathrm{f}_{0}$. The results show a close matching with the theoretical values. The deviation at higher frequency may be due to parasites of DOCCCII/CCCIIs. The time-domain response of the band pass filter is shown in Figure 8. Large signal behavior of the proposed filter is investigated by observing the dependence of the output total harmonic distortion (\%THD) upon the level of input signal. The result as illustrated in Figure 9, shows that the \%THD is well within the reasonable limit of 4\% [19] for input peak-to-peak voltage level of 2 V. Responses as shown in Figures 8 and 9 reveal that the output is of good quality.

\section{Conclusions}

In this paper a generalized nth order (where $n=2,3, \cdots, n$ ) voltage mode active-C filter topology is proposed. Both nth order band pass and low pass responses may be realized using same topology. The topology uses $n$ equal value grounded capacitors, single dual output current controlled current conveyor (DOCCCII) and (n-1) current controlled current conveyors (CCCIIs). The verification of the theory is performed by using AMS $0.35 \mu \mathrm{m}$ CMOS based DOCCCII/CCCII. Comparison with the reported publications [15-18] reveals that the proposed topology uses minimum number of active analog building blocks and minimum passive components. All of the used capacitors are grounded. It does not use any resistor and there is no requirement of changing any hardware for changing filter type from low pass to band pass or

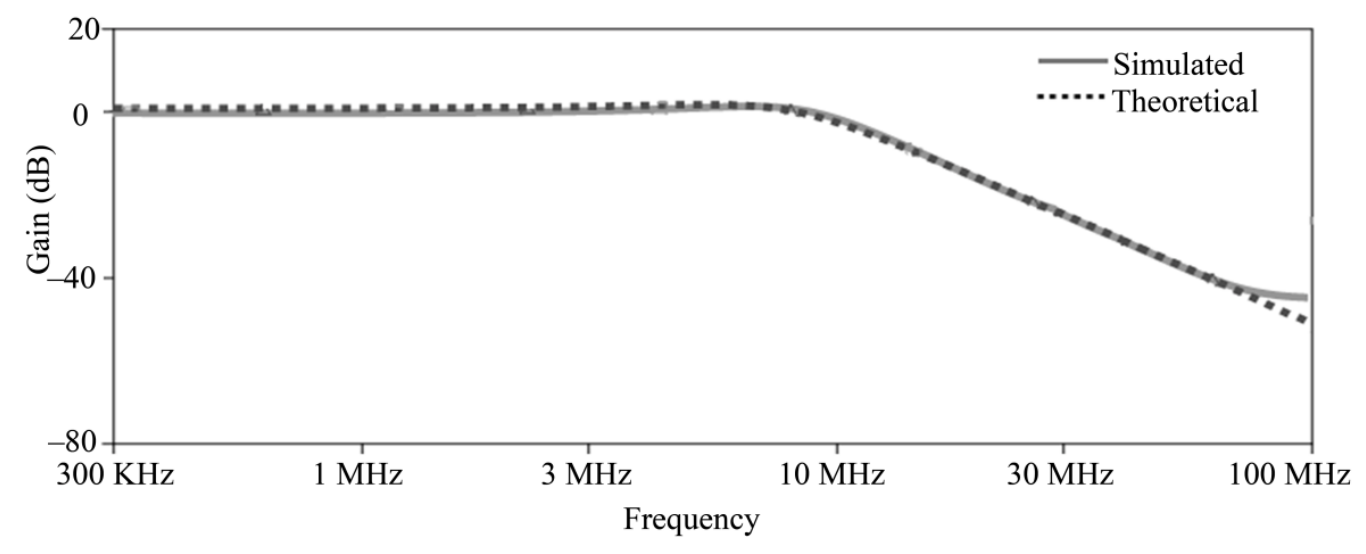

Figure 6. Frequency response of the third order low pass filter.

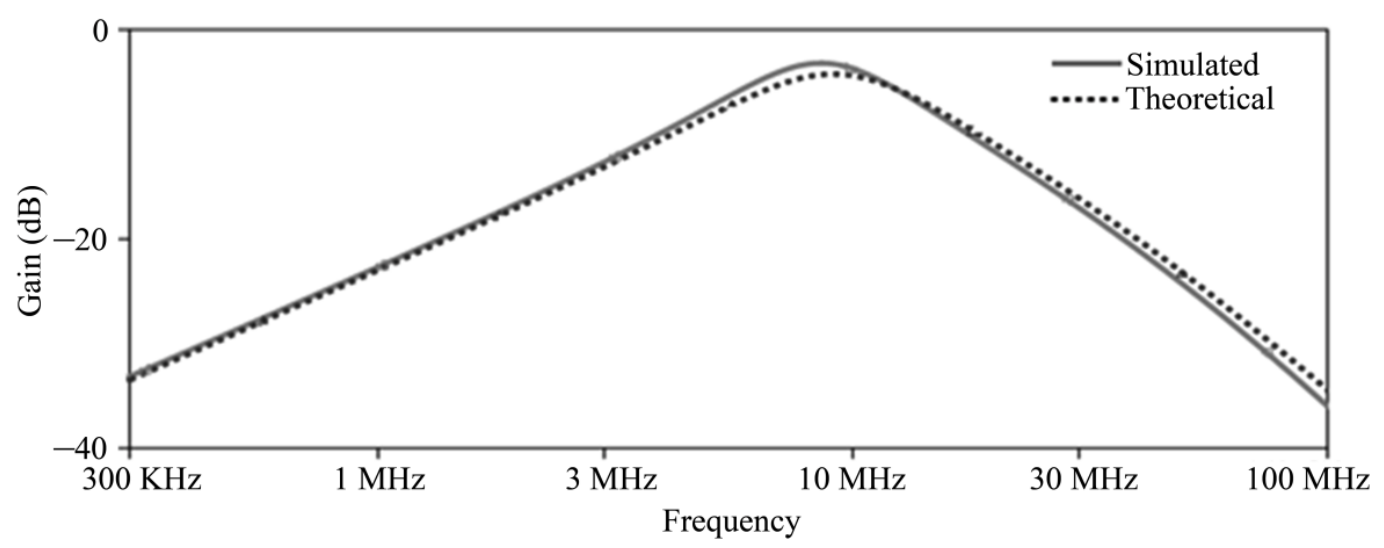

Figure 7. Frequency response of the third order band pass filter. 


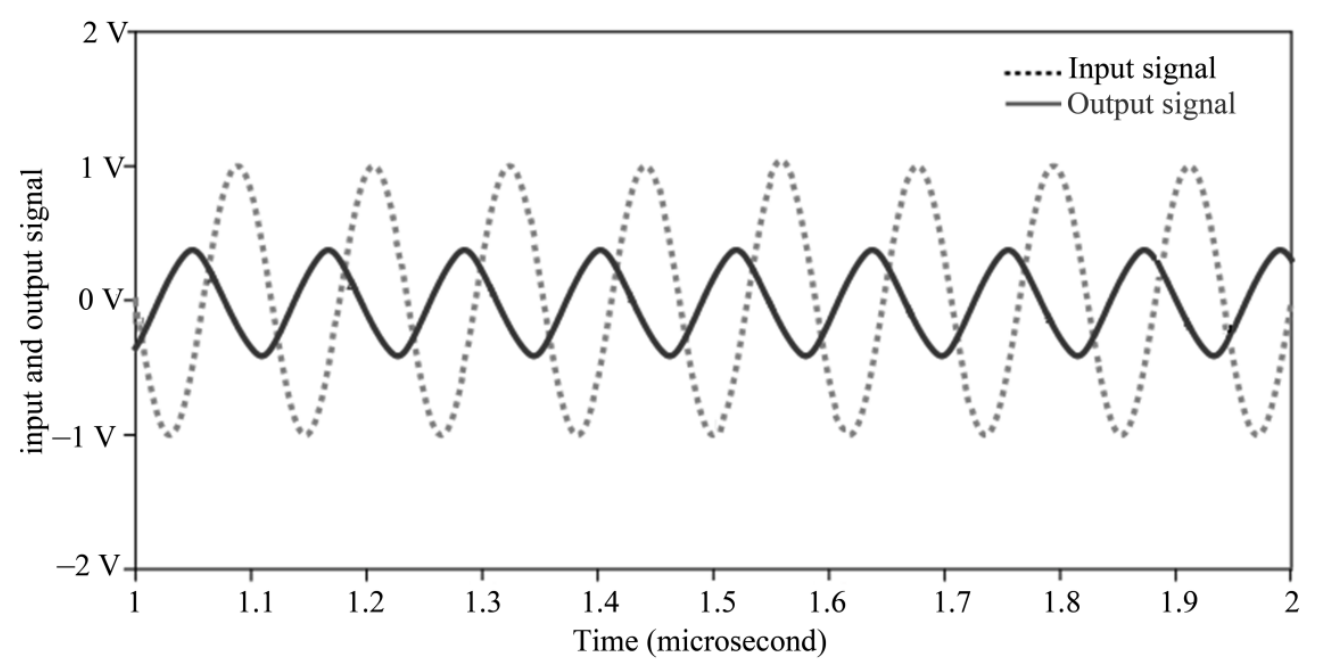

Figure 8. Time response of the band pass filter for input peak-to-peak voltage of $2 \mathrm{~V}$.

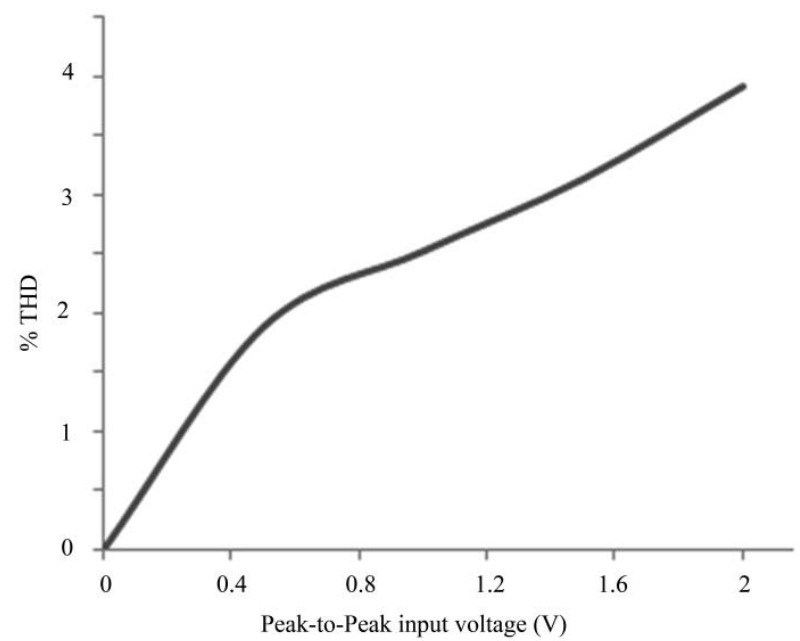

Figure 9. \% THD verses input voltage at $10 \mathrm{MHz}$.

vice-versa, hence suitable for monolithic IC implementation.

\section{References}

[1] C. Toumazou, F. J. Lidgey and D. G. Haigh, “Analogue IC Design: The Current-Mode Approach,” Peter Peregrinus Ltd, London, 1990.

[2] G. Ferri and N. C. Guerrini, "Low-Voltage Low-Power CMOS Current Conveyors,” Kluwer Academic Publishers, London, 2003.

[3] A. Fabre, O. Saaid and F. C. Boucheron, "Current Controlled Band Pass Filter Based on Translinear Conveyors,” Electronics Letters, Vol. 31, No. 20, 1995, pp. 1727-1728. doi:10.1049/el:19951225

[4] H. Barthelemy and A. Fabre, "A Second-Generation Current Controlled Conveyor with Negative Intrinsic Resistance," IEEE Transactions on Circuit Systems-I, Vol. 49, No. 1, 2002, pp. 63-65. doi:10.1109/81.974875
[5] E. Altuntas and A. Toker, "Realization of Voltage and Current Mode KHN Biquads Using CCCIIs,” International Journal of Electronics and Communication, Vol. 56, No. 1, 2002, pp. 45-49. doi:10.1078/1434-8411-54100071

[6] C. M. Chang, "Multifunction Biquardratic Filters Using Current Conveyors," IEEE Transactions on Circuit Systems-II, Vol. 44, No. 11, 1997, pp. 956-958. doi:10.1109/82.644049

[7] J. W. Horng, "High-Input Impedance Voltage-Mode Universal Biquardratic Filter Using Three Plus-Type CCIIs," IEEE Transactions on Circuit Systems-II, Analog and Digital Signal Processing, Vol. 48, No. 10, 2001, pp. 996-997.

[8] A. K. Singh and R. Senani, "A New Four-Cc-Based Configuration for Realizing a Voltage-Mode Biquad Filters,” Journal of Circuits, Systems and Computers, Vol. 11, No. 3, 2002, pp. 213-218. doi:10.1142/S0218126602000434

[9] Y. H. Wang and C. T. Lee, "Versatile Insensitive Current-Mode Universal Biquad Implementation Using Current Conveyors," IEEE Transactions on Circuit Systems-II, Analog and Digital Signal Processing, Vol. 48, No. 4, 2001, pp. 409-413. doi:10.1109/82.933806

[10] M. Koksal and M. Sagbas, "A Versatile Signal Flow Graph Realization of a General Current Transfer Function," AEU-International Journal of Electronics and Communication, Vol. 62, No. 1, 2008, pp. 33-40. doi:10.1016/j.aeue.2007.02.003

[11] M. Altun, H. Kuntman, S. Minaei and O. K. Sayin, "Realization of Nth-Order Current Transfer Employing ECCIIs and Application Examples," International Journal of Electronics, Vol. 96, No. 11, 2004, pp. 1115-1126. doi:10.1080/00207210903269047

[12] A. A. Hussain, A. N. Tasadduq and A.-E. Osama, "Digitally Programmable High-Order Current-Mode Universal Filteres," Analog Integrated Circuits and Signal Processing, Vol. 67, No. 2, 2010, pp. 179-187.

[13] H. Kuntaman, O. Cicekoglu and S. Ozcan, "Realization 
of Current-Mode Third Order Butterworth Filters Employing Equal Valued Passive Elements and Unity Gain Buffers," Analog Integrated Circuits and Signal Processing, Vol. 30, No. 3, 2002, pp. 253-256.

doi:10.1023/A:1014488619452

[14] E. Yuce and S. Minaei, "On the Realization of High-Order Current Mode Filter Employing Current Controlled Conveyors," Computers and Electrical Engineering, Vol. 34, No. 3, 2008, pp. 165-172. doi:10.1016/j.compeleceng.2007.04.001

[15] E. O. Gunes and F. Anday, "Realization of Nth-Order Voltage Transfer Function Using CCII+," Electronics Letters, Vol. 31, No. 13, 1995, pp. 1022-1023. doi:10.1049/el:19950751

[16] C. Acar, "Nth-Order Low Pass Voltage Transfer Function Synthesis Using CCII+s: Signal-Flow Graph Approach," Electronics letters, Vol. 32, No. 3, 1996, pp.159-160. doi:10.1049/el:19960136
[17] C. Acar and S. Ozoguz, "High-Order Voltage Transfer Function Synthesis Using CCII+ Based Unity Gain Current Amplifiers," Electronics letters, Vol. 32, No. 22, 1996, pp. 2030-2031. doi:10.1049/el:19961359

[18] J. Zaho, J. G. Ziang and J. N. Liu, "Design of Tunable Biquadratic Filters Employing CCCIIs: State Variable Block Diagram Approach,” Analog Integrated Circuits and Signal Processing, Vol. 62, No. 3, 2010, pp.397-406. doi:10.1007/s10470-009-9348-0

[19] E. S. Erdogan, R. O. Topaloglu, H. Kuntaman and O. Cicekoglu, "New Current Mode Special Function Continuous-Time Active Filters Employing Only OTAs and OPAMPs,” International Journal of Electronics, Vol. 91, No. 6, 2004, pp. 345-359. doi:10.1080/002072140410001695237 